\title{
Ecoturismo como valor patrimonial de resignificação do lugar: a experiência na chapada Diamantina-BA
}

\section{Lucas Bezerra Gondim ${ }^{1}$ e Christian Dennys Monteiro de Oliveira ${ }^{2}$}

1 Mestre em Geografia pelo PROPGEO/UFC, Brasil. E-mail: lucasgeoufc@gmail.com

2 Professor Adjunto II do Departamento de Geografia da UFC, Brasil. E-mail: cdennys@gmail.com

\begin{abstract}
RESUM0: Este trabalho consiste em tratar de uma modalidade do turismo ecológico, diferenciada da visão mais convencional. Considera perspectivas da educação patrimonial a partir de vivências exploratórias, realizadas em 2014, na Chapada Diamantina, estado da Bahia. Evidenciaremos as potencialidades do ecoturismo associado às formas de valorização do lugar simbólico como espaço de ressignificação do patrimônio natural. Embora a relação entre esta prática turística e a educação já tenha sido debatida por alguns autores, buscamos um olhar alternativo, no qual esta atividade de lazer/ensino requalifica o patrimônio, na perspectiva do turista, enquanto lugar. Para tanto estreitamos diálogos entre autores que discutem o lugar e o patrimônio natural na abordagem cultural da Geografia.
\end{abstract}

Palavras-chave: Patrimônio natural; Ecoturismo; Educação patrimonial; Chapada Diamantina; Lugar

\begin{abstract}
This work is to treat a form of eco-tourism, distinguished from the more conventional view. Considers perspectives of heritage education from exploratory experiences, held in 2014 , in the Chapada Diamantina, Bahia. We'll show the ecotourism potential associated with forms of recovery of the symbolic place as reframing space of natural heritage. Although the relationship between this tourist practice and education has already been debated by some authors seek an alternative look at what this leisure activity / education redevelop the property, in the tourist perspective, while place. Therefore we strengthened dialogue between authors who discuss the place and the natural heritage in the cultural geography.
\end{abstract}

Keywords: Cultural heritage; Ecotourism; Education for heritage; Chapada Diamantina; Place

Sumário: 1 Introdução: algumas considerações sobre o ecoturismo e patrimônio natural; - 2 Arcabouço metodológico; - 3 Do não-lugar ao lugar: vivências na chapada Diamantina-BA; - 4. Do não-lugar ao lugar: sobre sentimentos e vivências; - 5 Considerações finais; - Referências

\section{INTRODUÇÃO: ALGUMAS CONSIDERAÇÕES SOBRE O ECOTURISMO E PATRIMÔNIO NATU- RAL}

O processo de globalização do capital e a evolução dos meios de comunicação facilitaram a troca e o choque de culturas, em diversas regiões do globo considerando expansão de 
espaço como simulacros (CARLOS, 1997). Os efeitos da cultura da mídia (KELLNER, 2001) também ampliaram o leque de costumes, crenças, vestimentas e modos de vida que estão presentes em vários meios informacionais superando barreiras espaciais. 0 processo de integração global aumenta a comunicação entre culturas, o que torna culturas locais sujeitas a sofrerem reformulações que as adaptam ao desenvolvimento constante que atua nas sociedades. Porém, diante da intensa velocidade e aceitação deste processo, o fenômeno da "aldeia global" ganha notoriedade, onde as relações e comunicações entre as cidades são contínuas, permitindo manter a atualidade das palavras de Dardel (2011, p. 10) ao apontar: "Este 'encurtamento do mundo' perturbou todos os dados políticos e econômicos, criando uma interdependência planetária".

No encurtamento Dardeliano, o conhecimento de novas culturas e lugares, promovem uma aproximação (não apenas virtual) entre coletividades e contextos a partir da prática do turismo. Entretanto, nos limites convencionais, a prática turística é entendida apenas como "atividades realizadas por pessoas físicas durante viagens e estadas em lugares diferentes do seu entorno habitual, por um período inferior a 1 (um) ano, com finalidade de lazer, negócios ou outras"(M inistério do Turismo 2008). Enquanto isso, distanciando-se dessa visão burocrática, Telles $(2011$, p. 9) sinaliza que o turismo, como ecoturismo vem a ser

[...] um segmento da atividade turística que utiliza, de forma sustentável, o patrimônio natural e cultural, incentiva sua conservação e busca a formação de uma consciência ambientalista através da interpretação do ambiente, promovendo o bem estar das populações.

Partindo deste conceito, trazemos a proposta de dialogar com a perspectiva do ecoturismo, enquanto estratégia de vivência/manutenção e preservação do patrimônio natural. 0 conceito de ecoturismo é compreendido por Costa e Pinto (2012, p. 227) como uma atividade que busca:

Promover a realização de atividades de lazer e contemplação da natureza, atrelada à conservação e à Educação Ambiental. Contudo, apenas uma pequena parte das instituições que dizem promover um turismo atrelado ao conservacionismo, cumpre realmente o princípio básico que a atividade ecoturística procura desenvolver.

0 turismo ecológico é o segmento desta atividade que apresenta, simultaneamente, as maiores taxas/dados de crescimento, ambigüidades e contradições no seu processo de desenvolvimento sustentável que lidera o discurso desta prática (Almeida, 2008). A geógrafa sinaliza a busca do indivíduo morador da metrópole por uma aproximação da natureza não modificada ou não urbanizada na mesma intensidade que os grandes centros urbanos pelo homem, uma vez que:

Considerando que a natureza foi idealizada como realidade oposta à cidade e à vida citadina, o desejo de usufruir da natureza surge como justificativa para alguns, guiados pela necessidade de sentirem-se de acordo e em harmonia com o cosmos, com 0 
universo, com o ambiente e, sobretudo, com a consciência de "estar aqui". (ALM EIDA, 2008, 82)

Almeida utiliza o termo "naturofilia" para caracterizar este sentimento supracitado. Pensamos que não se trata apenas de uma dicotomia entre cotidiano urbano e natureza não modificada, mas sim de uma experiência do desconhecido, da "pureza" (Dardel, 2011), já que "ao mesmo tempo em que procura tornar as coisas próximas, o homem necessita de, por sua vez, se dirigir, para se reconhecer no mundo circundante, para se encontrar, para manter reta sua caminhada e para abreviar as distâncias", como afirma Dardel (2011, p. 11).

O ecoturismo ou turismo ecológico surge como uma renovação no segmento turístico, dando subsídio para a desconcentração dos destinos turísticos urbanos, já saturados pela falta de atrativos que as grandes cidades podem oferecer aos viajantes, com exceção do que já é sabido pelos turistas. Esta alternativa, potencialmente, auxilia no crescimento econômico local, principalmente em áreas com fraca relação econômica com a metrópole ou que não contenha o aparelhamento turístico padrão dos grandes centros urbanos receptores do turismo de massa. Segundo as Diretrizes para uma Política Nacional de Ecoturismo (1994), a atividade ecoturística tem como objetivos:

Compatibilizar as atividades de ecoturismo com a conservação das áreas naturais; fortalecer a cooperação inter-institucional; possibilitar participação efetiva de todos os segmentos atuantes no setor; promover e estimular a capacitação de recursos humanos para o ecoturismo; promover, incentivar e estimular a criação e melhoria da infra-estrutura para a atividade de ecoturismo e promover o aproveitamento do ecoturismo como veículo de educação ambiental.

A prática do ecoturismo não se limita à "venda de paisagens naturais", como apontam alguns autores com um discurso de conservação ambiental radical. Este segmento turístico integra uma carga de experiências vividas e sentidas pelo ecoturista, compreendendo este bem cultural como um patrimônio natural que "passou a ser entendido como conquista da sociedade, com um significado ligado às práticas sociais e à memória coletiva; portanto, um patrimônio natural que, antes de tudo, faz parte da vida humana e não algo que a ela se 0põe" (SCIFONI, 2006, p. 58).

O ecoturismo no Brasil é impulsionado entre 1985 e 1990, com os primeiros cursos de guia ecoturístico autorizados pela EM BRATUR, de acordo com o Guia de Turismo Brasil. Muitos fatores impulsionaram a expansão da prática do ecoturismo, como a Conferência Geral da Organização das Nações Unidas para a Educação, Ciência e Cultura, realizada em 1972, a Rio 92 alertando o mundo sobre os impactos ambientais gerados pela lógica de reprodução do capital no meio urbano e a criação da Associação Brasileira de Ecoturismo em 1998, hoje denominado como Instituto EcoBrasil, com o objetivo de tornar o Brasil um destino turístico confiável e sustentável com o intuito de realizar a manutenção e preservação do patrimônio natural.

O patrimônio natural vem sendo devastado pela expansão desordenada de um modelo "explosivo" de consumo e urbanização. 0 que faz com que as metrópoles e regiões metropo-

Planeta Amazônia: Revista Internacional de Direito Ambiental e Políticas Públicas 
litanas, em muitos casos, se tornem áreas excessivamente "cimentadas", com poucas áreas verdes, descaracterizando a herança cultural/natural de imensas áreas.

Destarte, precisa-se compreender que a criação de unidades de conservação ambiental, visando a proteção e preservação de bens naturais, constitui-se como um fenômeno contemporâneo, emergente de políticas públicas desde o final da década de 1970. Com as convenções mundiais realizadas entre a metade e o fim do século XX, tanto as propostas de proteção ambiental das áreas, como as voltadas à valorização patrimonial destes ambientes, sugerem interesses em legitimar uma outra ordem na relação sociedade/natureza. 0 que incide diretamente nos critérios utilizados para a proteção, como indicam Ribeiro e Scifoni (2006, p. 99) ao afirmarem que: "Os objetivos da preservação também foram sendo reorientados ao longo do tempo: da beleza excepcional passou-se a critérios ecológicos e a conservação da biodiversidade do planeta é o principal deles".

0 processo de valorização do meio ambiente enquanto patrimônio cultural natural ainda se mostra marginalizado no planejamento patrimonial da UNESCO, visto que

Internacionalmente há uma acirrada disputa entre os países para inscrição de seus bens de valor cultural na Lista do Patrimônio Mundial da Unesco. Já os patrimônios naturais só representam uma pequena parcela do interesse institucional para reconhecimento, 22\% do conjunto da lista até o ano de 2005 (SCIFONE, 2006, p. 57).

0 deslumbre por paisagens naturais em meio à um período de globalização e urbanização intenso é justificável, sendo, inclusive, uma estratégia das grandes cidades em tornar seus lócus de vegetação em pontos turísticos. Em localidades propícias às atividades ecoturísticas este sentimento se intensifica, principalmente pelo risco de extinção destes recortes espaciais. Esta prática se configura como um campo rico de pesquisas nos estudos geográficos uma vez que as formas de aproximação academias/comunidades locais se diversificam e se intensificam de forma significativamente articulada.

\section{ARCABOUÇO METODOLÓGICO}

0 planejamento para a realização das vivências exploratórias, de práticas do turismo ecológico, na Chapada Diamantina-BA, a priori, foi feito almejando o lazer. Contudo, já existindo 0 interesse em desenvolver pesquisas sobre o patrimônio cultural/natural, observou-se uma situação favorável ao estudo científico. A disponibilidade dos atores sociais contribuiu com a investigação proposta, visto que a estadia de 20 dias no território baiano se configurava suficiente para realizar a metodologia pretendida.

0 arcabouço metodológico consistiu, sobretudo, na experiência de ecoturistas em vivenciar esta atividade, caracterizando-nos enquanto pesquisadores-participantes, mantendo relações com os indivíduos envolvidos na prática ecoturística, subsidiando a descrição densa da atividade (GEERTZ, 1978). Realizaram-se registros fotográficos e audiovisuais dos pontos turísticos vivenciados e das cidades em que nos hospedamos. Aplicaram-se entrevistas com os representantes de agências de turismo dos municípios visitados, com guias de turismo, 
funcionários de mercados, restaurantes, proprietários de camping, ecoturistas. Além de conversas informais com moradores e o restante dos atores sociais envolvidos.

Este recorte de vinte dias ocorreu entre os dias 1 e 20 de julho de 2014. Onde se iniciou a trilha entre as cidades supracitadas, partindo da cidade de Lençóis em direção ao Vale do Capão, na cidade de Palmeiras, onde foi feito a trilha até o Vale do Pati e o retorno para 0 Vale do Capão.

\section{DO NÃO-LUGAR AO LUGAR: VIVÊNCIAS NA CHAPADA DIAM ANTINA-BA}

A Chapada Diamantina localiza-se na porção central do Estado da Bahia, abrangendo uma enorme área composta pela serra da M angabeira e do Espinhaço. Este conjunto geográfico pode ser dividido entre dois grupos: a parte voltada para economia agropastoril é denominada como zona agrícola, enquanto, a região que foi originada pela mineração, recebe 0 nome de zona lavrista. Nesta chapada lavrista foi criado o Parque Nacional da Chapada Diamantina, envolvendo os municípios de Lençóis, Mucugê, Andaraí, Ibicoara, Itaetê e Palmeiras. A conservação ambiental e cultural da chapada lavrista foram fundamentais para a realização do tombamento de algumas destas cidades, principalmente Lençóis - a primeira a se tornar patrimônio histórico nacional, em 1976, enquanto o Parque Nacional da Chapada Diamantina foi criado apenas em 1985, quase dez anos depois (GUANAES, 2006).

A prática de visitação à área da chapada é antiga, podemos observar no histórico do espaço estudado, uma vez que o garimpo era uma das principais atividades desenvolvidas na região e atraía indivíduos das localidades fronteiriças e de cidades vizinhas para explorar 0 espaço em busca de pedras preciosas, como sinaliza Guanaes (2006, p. 70).

Os dois acontecimentos embora distantes no tempo representam o início da vocação turística da região e marcam as primeiras discussões acerca da interação das populações humanas com os espaços naturais. É interessante observar que ambos os projetos, tanto o que reivindicou o título de Patrimôno Histórico Nacional à cidade de Lençóis quanto o que qualificou áreas naturais para a transformação em Parque Nacional, utilizaram-se de uma tradição histórica e cultural alicerçada na atividade do garimpo manual.

Além da história de ouro e diamantes, a Chapada Diamantina abrange uma vasta área de belezas naturais entre serras, cachoeiras e matas. Estas formações apontaram o potencial paisagístico do lugar, legitimado pelo Projeto RadamBrasil em 1981, idealizando a criação do Parque Nacional da Chapada Diamantina (PNCP) em 1982 e oficializando-se em 1985, durante o governo do presidente José Sarney através do Decreto 91.655 de 17 de setembro:

Fica criado no Estado da Bahia, o Parque Nacional da Chapada Diamantina, com o objetivo de proteger amostra dos ecossistemas da Serra do Sincorá, na Chapada Diamantina, assegurando a preservação de seus recursos naturais e proporcionando oportunidades controladas para uso pelo público, educação, pesquisa científica e também contribuindo para a preservação de sítios e estruturas de interesse histórico-

Planeta Amazônia: Revista Internacional de Direito Ambiental e Políticas Públicas 
cultural existentes na área.

A criação deste parque, mesmo há pouco mais de 30 anos, gera muitas discussões. As belezas das paisagens do Vale do Capão, Lençóis, Andaraí e outras cidades que constituem a chapada são interessantíssimas para o potencial turístico do lugar, contudo a criação de parques ou tombamento de patrimônios culturais não são dados para legitimação do processo, uma vez que: "parques não deveriam nascer de laudos técnicos e decretos e sim a partir das histórias vividas das pessoas reais, histórias que envolvem pessoas comuns, políticos, instituições, países e movimentos políticos e culturais" (GUANAES, 2006, p. 90). Este autor indica que existem muitas versões apoiadas em fatos que contam o processo de criação do PNCP de formas distintas, o que aquece mais os debates.

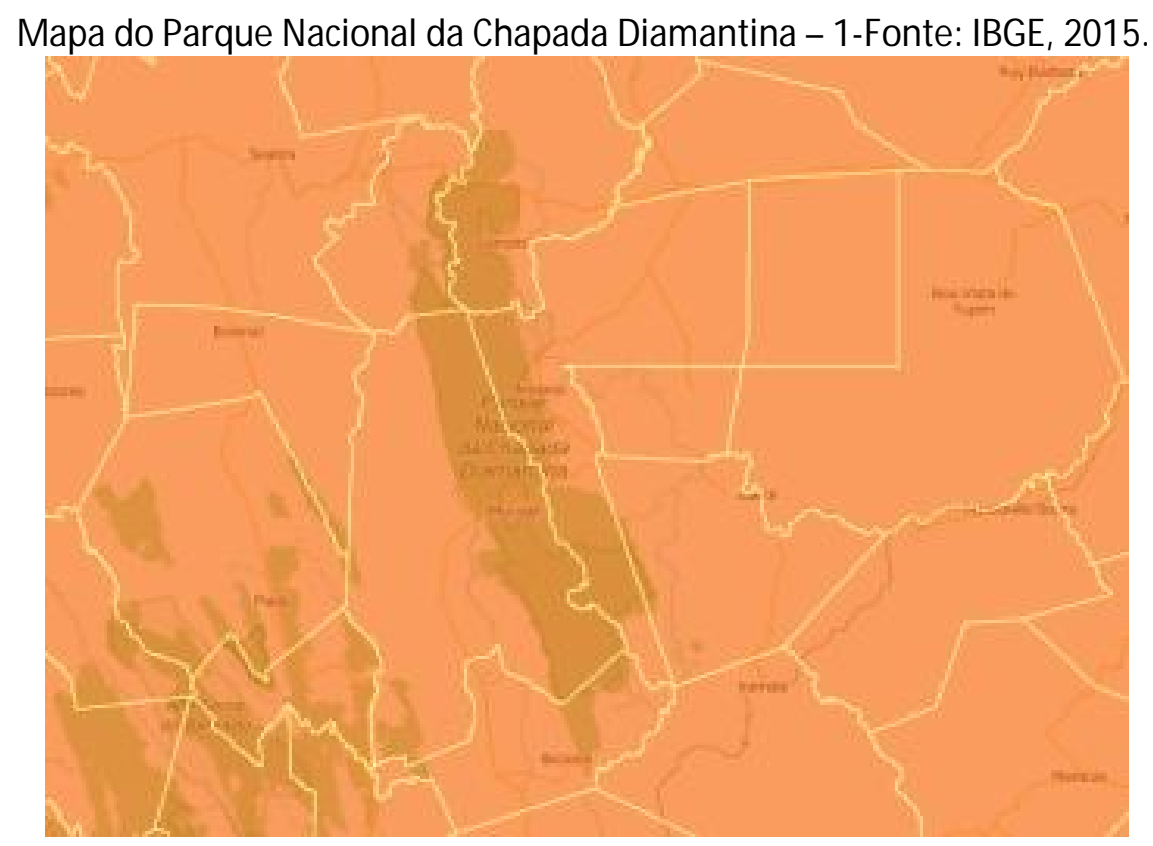

Chegando a Lençóis, pode-se perceber uma cidade voltada para o ecoturismo. Logo no desembarque do ônibus que realiza o percurso Salvador-Lençóis, uma quantidade significativa de guias turísticos aborda os passageiros que estão saindo do veículo, oferecendo a "guiada", como denominam, para a Cachoeira do Sossego e Ribeirão de Cima, as duas trilhas mais procuradas por ecoturistas, ambas com duração de um dia.

M uitos moradores na cidade de Lençóis "oferecem" suas casas como campings para os ecoturistas montarem seus acampamentos, visto que para realizar a trilha da Cachoeira do Sossego e de Ribeirão de Cima necessita-se de um dia, com saída pela manhã e retorno ao final da tarde/início da noite.

Lençóis, enquanto bem cultural nacional, tem sua organização sócioespacial semelhante à outras cidades tombadas, com pouco fluxo de carros e arquitetura simples, num movimento de preservar o molde arquitetônico do período de ocupação dos garimpos locais. 0 que induz seus visitantes à certa nostalgia sobre o lugar.

A cidade de Lençóis não foi uma das primeiras povoações formadas pelo garimpo de

Planeta Amazônia: Revista Internacional de Direito Ambiental e Políticas Públicas 
diamante na Chapada Diamantina, mas sem dúvida, foi a mais representativa de todas, transformando-se rapidamente em uma espécie de "capital das Lavras Diamantinas". A comercialização de diamantes para exportação e o surgimento do diamante "carbonato": um tipo de diamante mais bruto, usado na indústria, fizeram da cidade de Lençóis um centro econômico e político importante. (GUANAES, 2006, p. 78).

Na cidade de Lençóis, realizou-se apenas a trilha da Cachoeira do Sossego e a de Ribeirão de Cima, que está no percurso da primeira. 0 contexto histórico do lugar é revelado pelo guia turístico que transmite as histórias dos garimpeiros passadas de geração a geração para os moradores da cidade, como os pontos fortes da mineração, o transporte utilizado pelos garimpeiros e informações sobre a fauna e a flora do lugar.

A chegada à Cachoeira do Sossego (ver imagem 2) desperta um sentimento de deslumbre, devido à altura e beleza da queda d'água. Este sentimento é sentido até nas feições dos ecoturistas presentes no local. A trilha para chegar à cachoeira é cansativa e perigosa, exigindo conhecimento do guia, passado aos turistas, sobre o rio que se precisa percorrer para chegar ao destino. Esta reação de deslumbre se funde com a felicidade de ter conseguido atravessar um caminho tortuoso e conseguir chegar ao local desejado, a natureza desconhecida ou conhecida virtualmente apenas, que restringe o indivíduo que não a vive à um simples êxtase de beleza. Esta experiência confirma o discurso dardeliano sobre a relação telúrica entre o homem e a superfície terrestre.

A montanha responde a uma geografia ascensional da alma, a uma vocação pela "elevação" e a pureza. [...] 0 homem demanda à montanha um simbolismo da altura moral, ao mesmo tempo que a satisfação de uma vontade de escalar e ascender. Para os hindus, as geleiras cintilantes do Himalaia sustentam o trono inacessível de Shiva (DARDEL, 2011, p.17).

Cachoeira do Sossego - 2 - Fonte: Tavares, 2014.

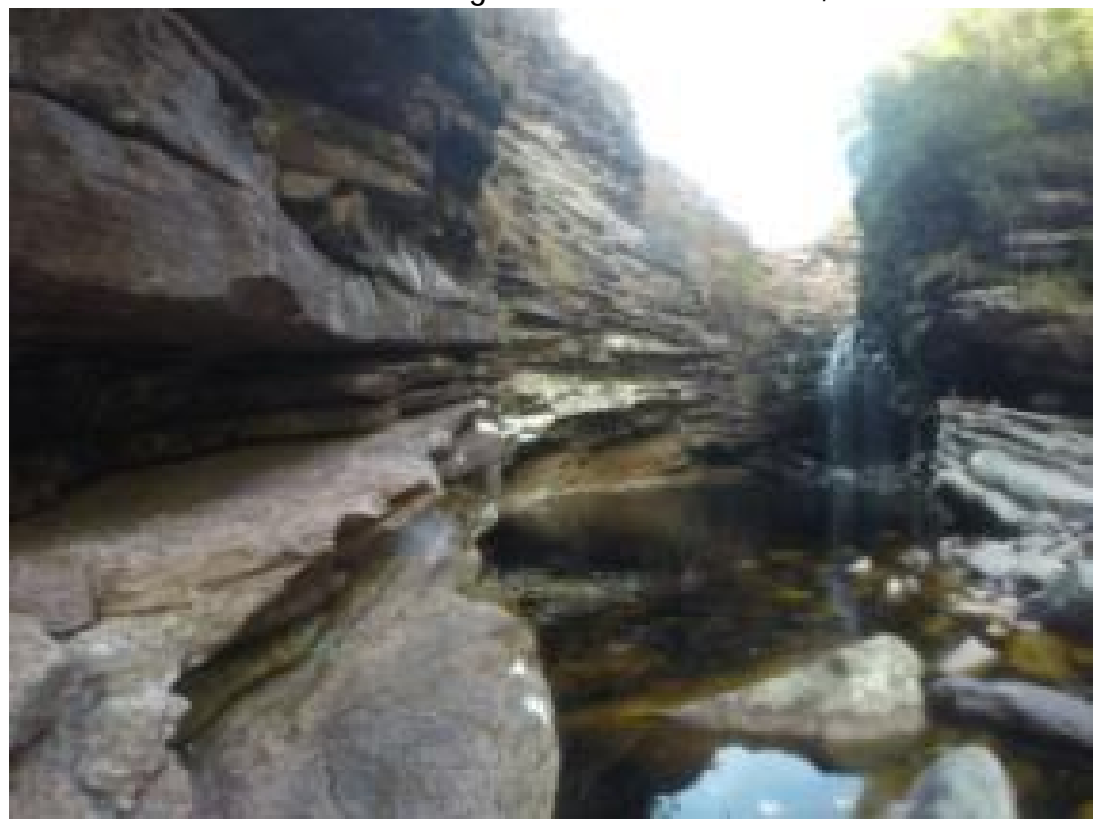

Planeta Amazônia: Revista Internacional de Direito Ambiental e Políticas Públicas 
No dia seguinte à visitação dos pontos turísticos da cidade de Lençóis, nos dirigimos para a cidade de Palmeiras, onde se localiza o Vale do Capão, um dos destinos mais procurados pelos ecoturistas, segundo os agentes turísticos do lugar. A organização sócio-espacial do Vale do Capão é semelhante à de Lençóis, mas com mais características de "vila" do que de cidade. Devido à pequena área da cidade, o fluxo de automóveis consiste primordialmente por motocicletas e transportes intermunicipais.

Chama atenção no "Capão" a área ocupada pelos campings e a quantidade destes que remete à alta demanda em períodos de intenso fluxo turístico, sendo os mais procurados 0 Camping do Seu Dai e o Camping Sempre-viva (nome que faz referência à uma formação vegetal típica da chapada) por conta dos preços favoráveis e o ambiente simples que seduz os ecoturistas que procuram viver em contato mínimo com o luxo da metrópole, pois vale ressaltar a presença de várias pousadas que oferecem todos os serviços (em menores proporções) que os de hotéis.

Os campings supracitados são espaços de convivência e de repouso dos ecoturistas que buscam o turismo ecológico, uma vez que as barracas ficam próximas, fazendo com que aconteçam encontros entre os ecoturistas, mesmo que efêmeros. Esta troca de vivências e socialização entre os indivíduos com uma atividade de lazer permite experiência como a de Renato e Vinicíus, dois ecoturistas que se conheceram na Chapada dos Veadeiros-GO e desde então planejam estas práticas, como esta ao Vale do Capão no período em que realizamos a pesquisa.

Diferentemente de Lençóis, o "Capão", por ser um vale, tem mais opções de trilhas, como a Cachoeira de Rodas, a Cachoeira das Angélicas, Cachoeira da Fumaça, a Ponte Velha, o Rio Preto. Esta variedade de focos de ecoturismo atrai ecoturistas de to do o Brasil. A estada no Camping Sempre-viva permitiu-nos conhecer e realizar conversas informais com ecoturistas de diferentes estados e com turistas de países da América Latina, principalmente. 0 guia turístico que nos acompanhou e guiou nas trilhas realizadas chegou até o camping buscando ecoturistas recém-chegados. Ele explicou a tensão que existe entre os moradores da Chapada que, conhecendo o lugar e as trilhas há anos, trabalham clandestinamente como guias e estão "perdendo mercado" para os guias turísticos contratados pelas agências existentes no Capão, que tem no ecoturismo sua base econômica. Pensando neste segmento turístico na perspectiva da experiência, os guias nativos da Chapada Diamantina têm muito a acrescentar nas vivências ecoturísticas e nos saberes tradicionais, visto que os guias das agências em sua maioria são naturais da capital baiana, segundo alguns guias nativos.

As mudanças socioeconômicas vinculadas ao turismo possibilitaram a inclusão social de parte das comunidades tradicionais, cujos membros das famílias trabalham em atividades de recepção ao turista, guias, serviços nos hotéis e pousadas, disponibilizando e adaptando as residências para acomodação dos visitantes. (SEABRA, 2012, p. 30)

0 primeiro ponto visitado enquanto estivemos acampados no Capão foi a Cachoeira da Fumaça, onde o conhecimento local novamente se evidenciou durante o decorrer da trilha,

Planeta Amazônia: Revista Internacional de Direito Ambiental e Políticas Públicas 
com explicações sobre a flora de relevos elevados e a fauna existente ali, visto que a Cachoeira da Fumaça é a segunda cachoeira mais alta do Brasil.

Cachoeira da Fumaça - 3 - Fonte: Moreira, 2014.

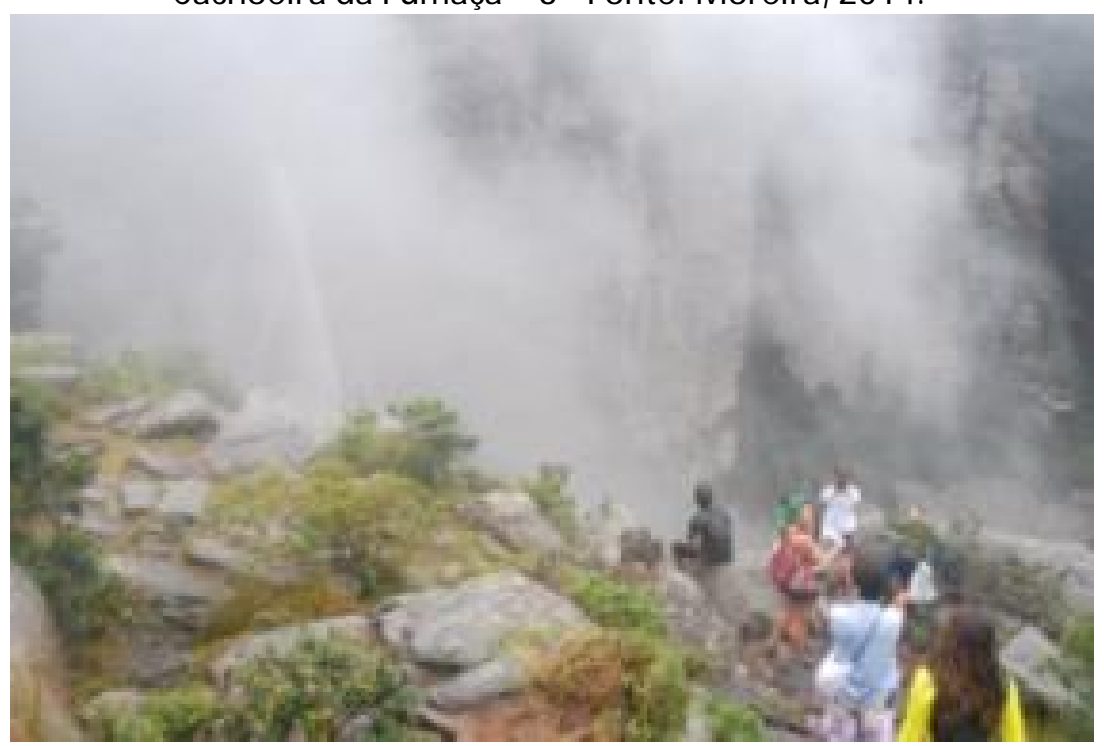

Nos dias seguintes realizamos as trilhas da Cachoeira de Rodas, o Rio Negro e a Ponte Velha, onde a memória do período do garimpo se materializa em resquícios dos utensílios utilizados para a pratica garimpeira que ainda se encontram pela mata e nas cachoeiras. A história da Chapada Diamantina lavrista está contida nas trilhas e nos pontos ecoturísticos, que com o auxílio dos guias nativos é revelada no decorrer da prática turística.

Cachoeira de Rodas - 4 - Fonte: M oreira, 2014.

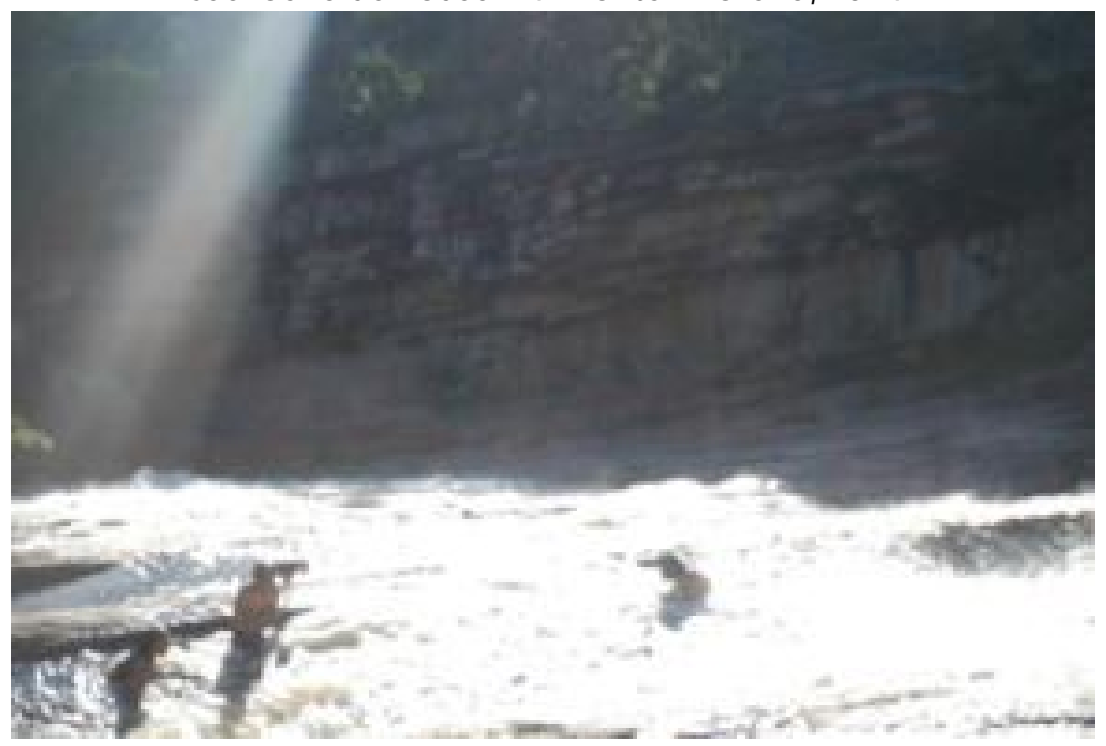

Reservamos uma dedicação na descrição da última experiência no Parque Nacional da Chapada Diamantina, por se caracterizar como uma prática de trekking, ou seja, uma ativida- 
de turística semelhante às caminhadas nômades, onde a trilha é realizada do período matutino ao início do período noturno, onde os ecoturistas fazem uma pausa no trajeto e descansam durante noite no acampamento montado pelo grupo. Desta forma, a geograficidade proposta por Dardel (2011) se evidencia uma vez que nesta perspectiva o indivíduo depende direta ou indiretamente da Terra para suas necessidades básicas.

Na semana final de práticas ecoturísticas, realizou-se o trekking com saída do Vale do Capão para o Vale do Pati e retornando para o Capão, uma travessia de aproximadamente 80 $\mathrm{km}$ com estimativa de ser realizada em quatro dias. Esta atividade foi desempenhada por um grupo de 11 indivíduos, com o auxílio do mesmo guia. Devido a distância percorrida, pôde-se observar diferentes tipos de vegetação e relevo. Os guias clandestinos, segundo os indivíduos entrevistados, "envolvem" o ecoturista nas vivências do local, enquanto os contratados pelas agências não cumprem essa função com a mesma perspicácia ou interesse. Estes se comprometem, a priori, com o auxílio nas trilhas, como as bifurcações e os trechos tortuosos.

Pudemos perceber esta afirmação durante a práxis. No percurso da trilha, ao adentrar num resquício de mata atlântica em meio ao cerrado, o guia explicou que os garimpeiros viam na entrada desta formação uma espécie de "portal" natural, devido à diferença sensível na temperatura e na vegetação ao entrar na Floresta do Calixto (assim denominada pelos moradores da Chapada Diamantina).

No primeiro dia de caminhada o grupo se dirigiu até a Floresta do Calixto, local onde passaríamos a primeira noite. 0 telurismo dardeliano se legitima novamente. Após caminharmos $28 \mathrm{~km}$ e nos acomodarmos, o semblante de exaustão era tão nítido quando o de satisfação por se aventurar rumo ao desconhecido, perceptível na fala de um dos ecoturistas ali presentes: "Caramba, a gente ta aqui no meio de uma floresta, sem celular, nem energia, só essa lua enorme iluminando tudo".

As relações entre o homem e a Terra tornaram-se perceptível neste primeiro dia de atividades, quando se utilizou a cobertura vegetal para proteger as barracas da chuva, a fogueira preparada para espantar animais silvestres e/ ou peçonhentos e esquentar os alimentos carregados nas mochilas. Neste ponto percebe-se a geograficidade, uma vez que sem 0 subsídio fornecido pela natureza e o saber local do guia a trilha planejada se comprometeria, assim como a segurança dos ecoturistas.

Visto que a Terra é a mãe de tudo o que vive, de tudo que é, um laço de parentesco une o homem a tudo que o cerca, às árvores, aos animais, até as pedras. A montanha, o vale, a floresta não são simplesmente um quadro, um "exterior", mesmo que familiar. É lá que se realiza e se conhece. (DARDEL, 2011, p. 49) 


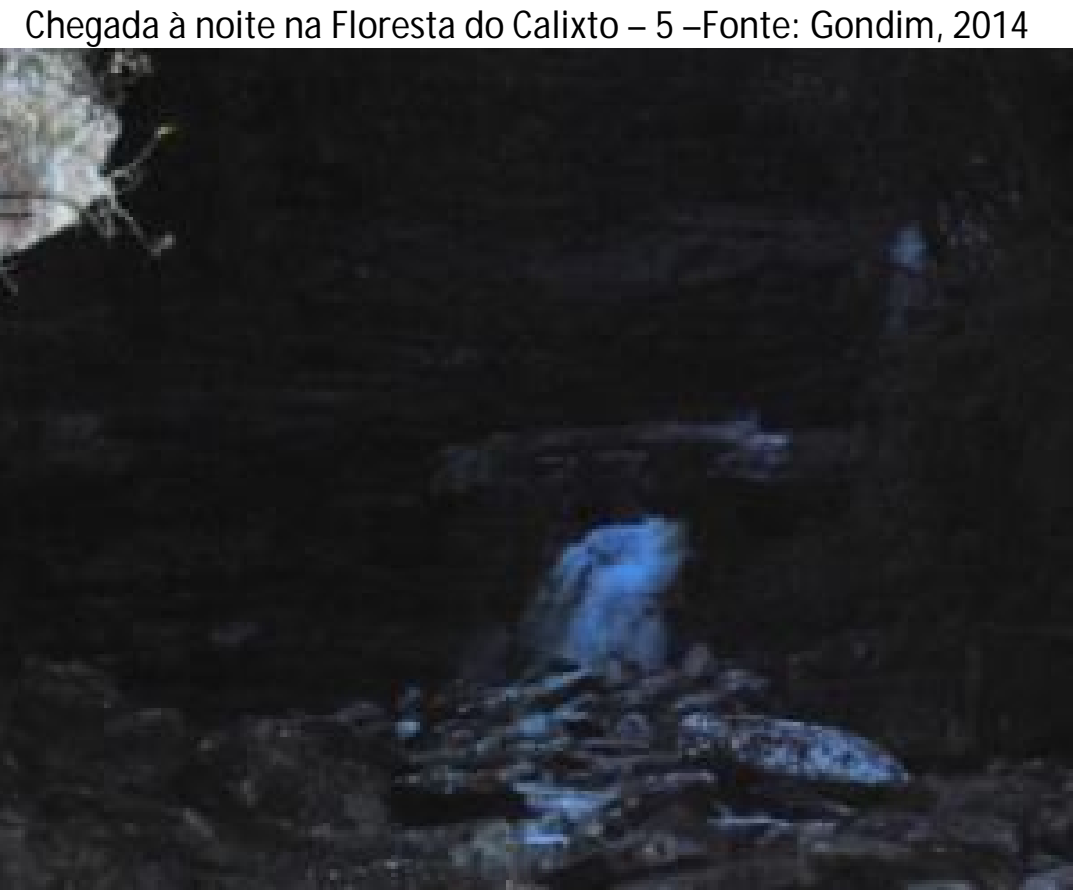

O segundo dia desta trilha até o "Pati" consistia na chegada ao M orro do Castelo, lugar estimado para chegarmos durante o início da noite. Neste percurso nos deparamos com uma trilha construída pelos garimpeiros, onde estes utilizavam burros para transportar os diamantes e, segundo o guia, ainda hoje alguns moradores da região encontram pedras preciosas soterradas nestes caminhos. Frutas puderam ser colhidas no local, que serviram de alimento para o grupo, que devido ao peso das mochilas, levam poucos alimentos, em sua maioria refeições equivalentes à almoço e janta, como comidas instantâneas, pães, carnes cruas para serem preparadas na fogueira, dentre outros.

Os caminhos turísticos continuam com os saberes compartilhados sobre o histórico do lugar. 0 M orro do Castelo é fundamental para nos localizarmos em meio à vasta paisagem observada, devido à imponência desta elevação. No trajeto em direção ao Castelo, nos deparamos com o Poço da Árvore, um lago escondido em meio à mata fechada, onde acreditavase que ao pular de uma árvore (que indica o nome do lugar) o indivíduo recebia uma espécie de purificação dada pela natureza, segundo o guia. 0 envolvimento com o lugar se revela quando todos os ecoturistas pularam da árvore em direção ao poço, no anseio desta purificação mítica.

Chegando a Morro do Castelo, após mais um dia de jornada, cumprindo $42 \mathrm{~km}$ (somando-se ao primeiro dia de caminhada), o sentimento de fascinação por se encontrar naquela situação ainda se aflorava, principalmente após participar do ritual no Poço da Árvore. Ao montar 0 acampamento, as relações entre o homem e a Terra novamente se evidencia, uma vez que, à partir deste dia, a água potável utilizada consistia das nascentes dos rios e cachoeiras, sinalizadas pelo guia como aptas para beber. Além da utilização da fogueira para 0 aquecimento dos participantes e para cozinhar os alimentos. 
"Purificação" no Poço da Árvore - 6 -Fonte: M oreira, 2014

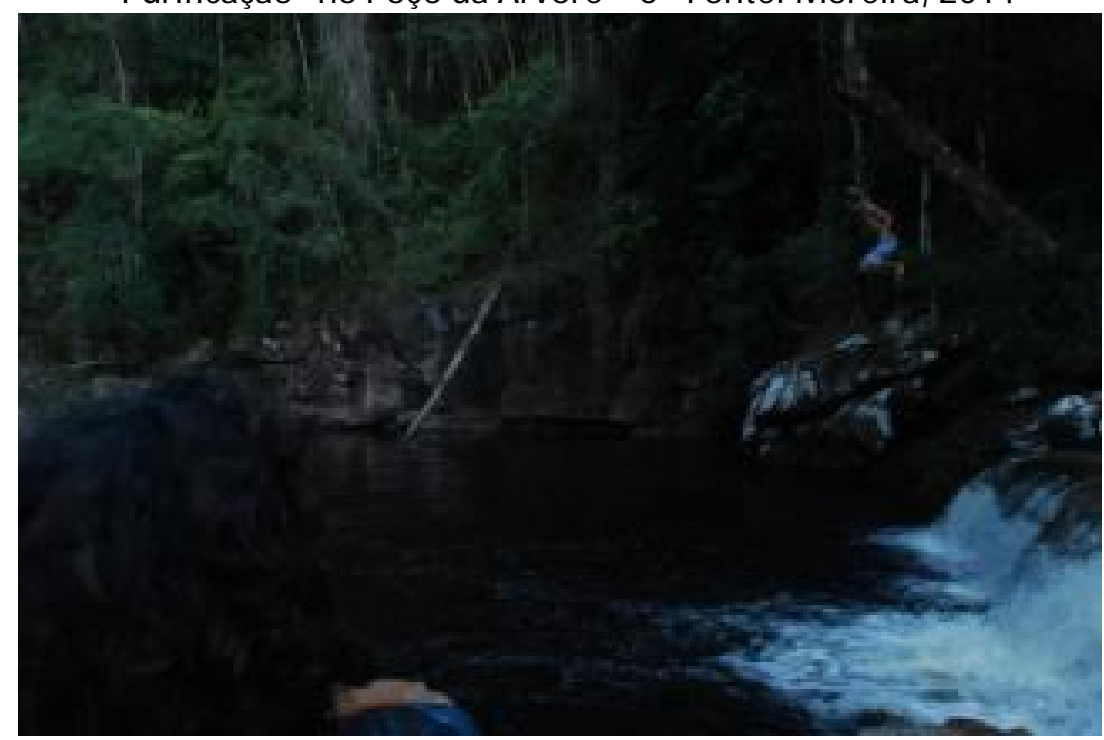

0 terceiro dia em que pernoitamos no Pati completamos cerca de $70 \%$ do percurso, onde seguimos utilizando a água das nascentes para hidratação e banho. Este percurso foi marcado por subidas íngremes e exaustivas, a ponto da trilha ser interrompida em diversas ocasiões por alguns dos membros do grupo não terem condições de continuar o caminho até a Toca do Gavião, local onde armamos o último acampamento antes de voltarmos para o Vale do Capão. Evidentemente os escritos de Dardel (2011), mais uma vez se mostraram na práxis, visto a chegada no ponto de destino e o sentimento dos ecoturistas frente 0 alpinismo realizado:

0 alpinismo não é somente um esporte levado às vezes até a temeridade. Ele é também, nessa mesma paixão, um conhecimento interior à ação, um conhecer pelo agir, uma apreensão da Terra como espaço telúrico, através do esforço, da conquista e do perigo. (DARDEL, 2011, p. 17).

A Toca do Gavião se constitui enquanto uma "lareira" segundo o guia, um espaço natural de pernoite, onde 0 teto e o solo da morada se caracterizavam por uma formação rochosa, que servia de abrigo para alguns dos garimpeiros que realizavam a prática no Vale do Pati. 0 saber sobre a Toca passado da atividade do garimpo para os moradores foi fundamental para o êxito de nossa estada neste lugar, visto que além de um abrigo e com nascentes próximas (fornecendo água potável), é um lugar propício ao aparecimento de animais silvestres e peçonhentos. Desta maneira, a fogueira se torna essencial para espantá-los com a fumaça, além de aquecer o grupo e cozinhar os alimentos.

No último dia de caminhada seguimos de volta para o Vale do Capão, onde a exaustão e o semblante abatido dos andarilhos era evidente após realizar o percurso de aproximadamente $80 \mathrm{~km}$ em 4 dias, mas o deslumbre e a felicidade de ter se deparado com situações inesperadas, temperaturas intercaladas entre 30 e 14 graus Celsius, as elevações tortuosas completadas com sucesso e a utilização do lugar e dos saberes locais para suprir suas neces- 
sidades básicas também são evidenciados nos discursos de alguns indivíduos do grupo.

Ao chegar desta prática de trekking ao Vale do Capão, o guia forneceu sua residência para continuarmos até o dia marcado do retorno para Fortaleza-CE, em que vivenciamos três dias de experiências do cotidiano dos moradores nativos do Vale do Capão.

\section{DO NÃO-LUGAR AO LUGAR: SOBRE SENTIMENTOSE VIVÊNCIAS}

Na perspectiva humanista, a que nos debruçamos nesta atividade de campo, o lugar segundo Tuan (2012) está relacionado às experiências e sentimentos topofílicos e topofóbicos. Como o autor indica: Os estímulos sensoriais são potencialmente infinitos: aquilo que decidimos prestar atenção (valorizar ou amar) é um acidente do temperamento individual, do propósito e das forças culturais que atuam em determinada época (TUAN, 2012, p. 161). Partindo deste pressuposto, podemos arquitetar uma pirâmide sobre a perspectiva de lugar sinalizada com esta atividade de campo, conforme quadro síntese apresentado a seguir.

Entendendo o pressuposto humanista de Tuan e a relação do indivíduo (ecoturista) com o lugar (tornado simbólico), observa-se que este sentimento de pertencimento que envolve 0 homem e o espaço (terra) não emerge apenas a partir da longevidade no local, mas sim que este pode aflorar a partir do temperamento interativo dos visitantes, uma vez que "os lugares atravessam memórias vivas" (CANDAU, 2012, p. 157).

A partir desta sinalização de Candau, pensemos numa discussão triangular sobre as 0bras de Relph (1976), Dardel (2011) e Tuan (2012; 2013).

Quadro síntese do lugar - 8 - Fonte: Gondim; Oliveira 2016.

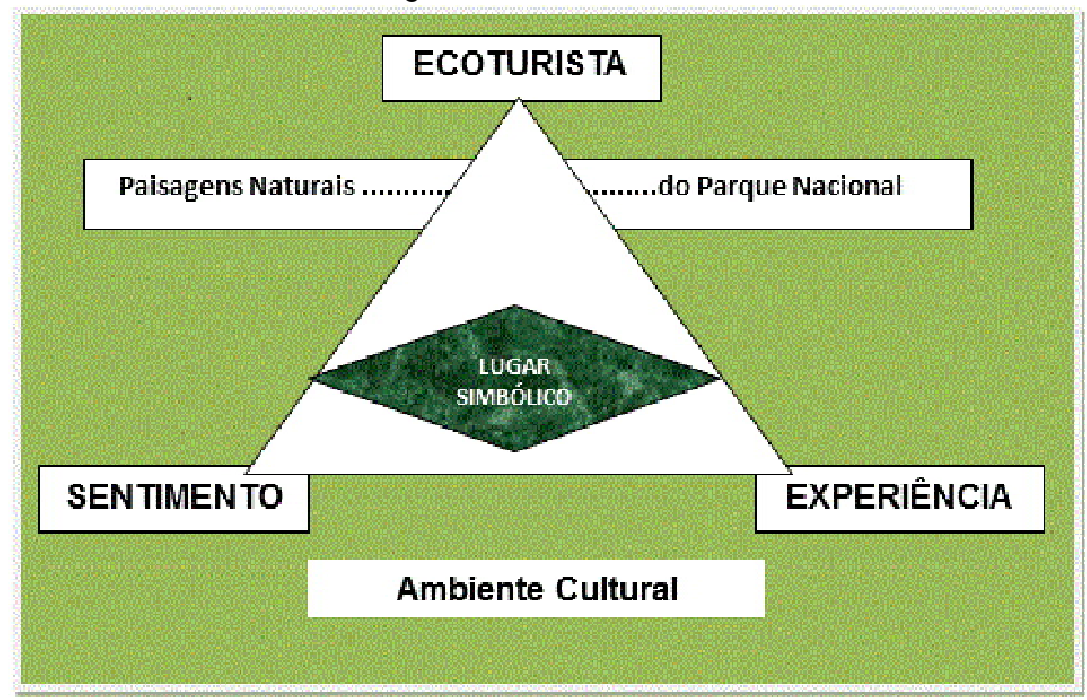

Num debate sobre lugar, pensemos em Relph (1976) e na sua ideia de "deslugares". Brum (2015, p. 4) afirma que Relph considera que tal processo indicaria que estaríamos presenciando um "enfraquecimento das qualidades simbólicas dos lugares e das paisagens diferenciadas, o que permitiria falar de uma geografia da "deslugaridade"". Tuan (2013) indica que, na perspectiva da experiência, espaço e lugar frequentemente se fundem, pois o que 
começa como espaço indiferenciado transforma-se em lugar à medida que o conhecemos melhor e o dotamos de valor (TUAN, 2013, p. 14).

Pensemos no desconstruir para construir: na perspectiva de Relph, o "deslugar" se constitui como um lugar não dotado ou com poucas qualidades simbólicas frente às paisagens diferenciadas e lugares simbólicos. Compreendendo a busca pelo desconhecido, ou ainda a naturofilia (ALM EIDA, 2008) enquanto força que influencia o ecoturista a realizar a atividade, questionamos: qual o valor simbólico dos parques ambientais ou espaços propícios para a prática ecoturística de um visitante que a faz a primeira vez?Como Almeida (2008) sinaliza, o indivíduo procura o desconhecido, logo ele não tem relações afetivas com este espaço, seu lugar afetivo ou pelo qual ele constrói sentimentos são os espaços vividos, os lugares simbólicos que representam algum sentimento de pertencimento para ele, mesmo que se caracterizem enquanto "lugares de consumo".0 indivíduo constrói seus sentimentos quando experiência o lugar, uma vez que: os seres humanos são maduros ou imaturos dependendo de terem ou não tirado vantagens dos acontecimentos. Assim, a experiência implica a capacidade de aprender a partir da própria vivência. Experienciar é aprender (TUAN, 2013, p. 18).

Nesta perspectiva, o ecoturista que, cotidianamente, vivencia os lugares urbanos de consumo, de lazer, de trabalho e etc... Cria laços afetivos ou de necessidade com estes lugares, fazendo com o desconhecido (ou o conhecido virtualmente) se torne o não-lugar ou deslugar. Apesar de contrário ao discurso de Relph, esta noção de deslugar nos parece mais indicativa de um ambiente ausente de sentimentos, uma vez que estamos debatendo isto a partir da Geografia Humanística de Tuan.

Não discordamos de Tuan $(2012$, p. 97) quando este indica que "a avaliação do meio ambiente pelo visitante é essencialmente estética. É a visão de um estranho. 0 estranho julga pela aparência, por algum critério formal de beleza". A priori, o fascínio dos escoturistas se dá pela beleza singular das cachoeiras, matas e rios. No entanto os processos descritos acima no tópico anterior nos mostram que este processo de resignificação do lugar através da experiência se da subjetivamente. Não é algo pensado ou planejado, mas sim um fenômeno inconsciente aflorado pela práxis.

Fica evidente através dos discursos, das entrevistas e linguagem corporal dos indivíduos envolvidos nesta atividade turística que este processo se da através do insciente. Como as sensações compartilhadas ao encerrar o dia de caminhada e chegar ao ponto de montagem do acampamento, a exaustão somada à satisfação. 0 cansaço e conforto de deitar-se numa rocha à beira da cachoeira e sentir o frio proveniente da água enquanto admira o céu estrelado, que não se vê nas grandes metrópoles, e reconhecer-se enquanto parte daquela natureza desconhecida que reserva perigos, situações inesperadas, mas que também os presenteia com paisagens singulares, com 0 aconchego das matas, os banhos de cachoeira que "regeneram as energias físicas e espirituais" como cita uma das entrevistadas.

\section{CONSIDERAÇÕES FINAIS}

Esta experiência contemplou a complexidade que é discutir o patrimônio natural a par-

Planeta Amazônia: Revista Internacional de Direito Ambiental e Políticas Públicas 
tir de duas perspectivas que se entrecruzam, a preservação ambiental e o histórico cultural que contempla o lugar, somado à resignificação do lugar pensando as práticas ecoturísticas. Mas resignificação do lugar não se estabelece com o simples deslumbre da paisagem; e sim pelas relações entre e 0 individuo e a Terra que estabelecem a geograficidade dardeliana. Como se deparar com a necessidade de utilizar os recursos da superfície para realizar suas necessidades básicas, como se hidratar, alimentar, proteger, higienizar e dormir.

Contudo, para isto, se faz necessário entender o lugar na perspectiva humanística da Geografia, onde uma relação em forma de tríade entre o indivíduo, sentimento e a experiências compõem uma lugaridade do lugar, indicada por Relph (1976) e adaptada por nós na perspectiva humanística de Tuan $(2012 ; 2013)$.

Desta forma, se faz necessário entender que a prática ecoturística concebe em duas possibilidades: onde emerge uma interação entre o indivíduo/lugar, ou onde ela se restringe a uma aventura vazia, sem educação patrimonial. Nesta última, o envolvimento turístico dáse puramente pelo fascínio com as paisagens naturais, não construindo sentimentos nem ressignificação do lugar. Vale ressaltar que estas possibilidades se excluem. Logo, para ocorrer a aproximação entre ecoturista e lugar, a educação patrimônio aflora através do intermédio do guia local, colocando o ecoturista em contato e experiência com as comunidades locais.

\section{REFERÊNCIAS}

ALM EIDA, Maria Geralda de. Ambiguidades e contradições no discurso de naturofilia e nas práticas turísticas. Paraná: Desenvolvimento e M eio Ambiente, n 18, 2008.

BRUM, Jean Lucas da Silva. Entre lugares e deslugares: um olhar teórico a partir de Relph e Augé. Belo Horizonte: XVI ENANPUR, 2015.

CARLOS, Ana Fani Alessandrini. A construção de uma "nova urbanidade". IN: SILVA, José Borzacchiello da; COSTA, Maria Clélia Lustosa; DANTAS, Eustógio Wanderley. A cidade e o urbano. Fortaleza: EUFC, 1997.

COSTA, Vivian Castilho da; PINTO, Roberta Mariana Ferreira Mori. Ecoturismo e risco ambiental. Coimbra: Revista Territorium, no 19, 2012.

DARDEL, Eric. 0 Homem e a Terra: Natureza da Realidade Geográfica. São Paulo: Ed. Perspectiva, 2011.

GEERTZ, Clifford. Uma Descrição Densa: Por uma Teoria Interpretativa da Cultura. In: A interpretação das culturas. Rio de Janeiro: Zahar Editores, 1978. Cap. 1, p. 13-41.

GUANAES, Senilde Alcantara. Meu quintal não é o parque: populações locais e gestão ambiental no Parque Nacional da Chapada Diamantina-BA. 2006. 317 p. Tese. (Doutorado em Ciências Sociais) - Instituto de Filosofia e Ciências Humanas da Universidade Estadual de Campinas, Campinas. 2006.

RELPH, Edward. Place and Placelessness. London: Pion, 1976

RIBEIRO, Wagner Costa; SCIFONI, Simone. Preservar: para que e para quem? Rio Claro: Patrimônio e memória, vol 2, nำ2, 2006

SCIFONI, Simone. Os diferentes significados do patrimônio natural. Maringá: Diálogos, v. 10, 
n. 3, 2006

SEABRA, Giovanni de Farias. Natureza, cultural e turismo em unidades de conservação. IN: PORTUGUÊZ, Anderson Pereira; QUEIROZ, Odaléia Telles; SEABRA, Giovanni de Faris. Turismo, espaço e estratégias de desenvolvimento local. João Pessoa: Editora UFPB, 2012.

TELES, R. Turismo e meio ambiente ou turismo da natureza? Alguns apontamentos para organização dessa modalidade. in: TELES, R. Turismo e meio ambiente. Rio de Janeiro: Elsevier, 2011.

TUAN, Yi-Fu. Espaço e Lugar: a perspectiva da experiência. São Paulo: Eduel, 2013.

TUAN, Yi-Fu. Topofilia: um estudo da percepção, atitudes e valores do meio ambiente. São Paulo: Eduel, 2012.

Artigo recebido em 26 de agosto de 2016.

Aprovado em 31 de dezembro de 2016. 